\begin{tabular}{c} 
Volume and Issues Obtainable at Center for Sustainability Research and Consultancy \\
Sustainable Business and Society in Emerging Economies \\
ISSN: 2708-2172 (E): 2708-2504 \\
Volume 2: Issue 2 December 2020 \\
Jor \\
Journal homepage: $\underline{\text { www.publishing.globalcsrc.org/sbsee }}$ \\
\hline
\end{tabular}

\title{
Mediating Role of Training in Enhancing Awareness of SDGs, Economic, Environmental and Social Performance
}

\author{
${ }^{1}$ Madiha Shafique Dar, ${ }^{2}$ Safia Bano, ${ }^{3}$ Jameel Ahmed \\ ${ }^{1} \mathrm{PhD}$ Scholar, University of Balochistan, Pakistan, dar.madiha8@ gmail.com \\ ${ }^{2}$ Assistant Professor, University of Balochistan, Pakistan, sb_ims@ yahoo.com \\ ${ }^{3}$ Assistant Professor, University of Balochistan, Pakistan, Jamil_ims@yahoo.com
}

ARTICLE DETAILS

History:

Revised format: November, 2020

Available Online: December, 2020

\section{Keywords:}

Sustainable Development

Goals, Training, Sustainable

Performance, Economic

Performance, Environmental

Performance, Social

Performance

JEL Classification:

M11,M12
ABSTRACT

This paper aims to identify how awareness of SDGs affects sustainable performance and how training can assist to enhance the economic, environmental, and social performance of employees. The research study is conducted in a public sector institute with a population of 331 employees. Among 269 respondents participated in the survey. The data is analyzed using SPSS and Smart PLS. The result showed a significant relationship among the variables. The awareness of SDGs proved to be positively related to the social, economic, and environmental performance of the employees. Moreover, training also positively mediates the relationship between SDGs awareness and sustainable performance. The paper promotes public institutions to contribute their utmost efforts in achieving SDGs and create learning development experiences that assist employees to preserve cuttingedge knowledge and perform at their best.

\section{OPEN ACCESS}

(C) 2021 The authors, under a Creative Commons AttributionNonCommercial 4.0

Corresponding author's email address: dar.madiha8@gmail.com

Recommended citation: Dar, M. S., Bano, S., and Jameel, A. (2020). Mediating Role of Training In enhancing Awareness of SDGs, Economic, Environmental and Social Performance. Sustainable Business And Society in Emerging Economies, 2 (2), 41-50

\section{Introduction}

The concept of Sustainable Development Goals (SDGs) has gained increasing support and almost 193 member states of the United Nations have adopted SDGs as the organizing framework for global cooperation of development for the period 2015 to 2030 (Cf, 2015). Countries are concern that the world economy is not on a satisfactory path and it needs greater effort to make the future more meaningful and productive not only in terms of economic boost but also in terms of technology, environment, and social factors. Globally, countries are facing environmental threats such as global warming, loss of biodiversity, deforestation, and severe climate changes (Huan et al., 2019). Similarly, widening inequalities between the rich and poor and social exclusion are noticeable. These matters are worrisome but can be tackle. SDGs are one of the steps towards shared prosperity, wellbeing, and development. Where the present and future generations can enjoy all the privileges of life without compromising (Chams \& García-Blandón, 
2019). In short, it is a concept of improving the well-being of today's generation and also for the generations to come. SDGs are visualized as a path for the world in which prosperity is shared, societies are inclusive, and the environment is protected and safe, and where technologies and infrastructure is not impinging the physical earth processes but with its efficient and effective use it helps reset the direction of the world economy. Like many of the SDGs are ending deprivation, ensuring universal access to health and quality education. Almost all the goals are of profound significance that's why it is called "Transforming the world: the 2030 Agenda for sustainable development" and it has the following statement of purpose "This agenda is a plan of action for people, planet and prosperity" i.e. people, planet, and prosperity (Oosterhof, 2018). Simply, it is the social inclusion of the planet along with environmental sustainability and prosperity that is a shared economic benefit across the globe. Agenda 2030 also seeks to strengthen the universal peace in larger freedom. It is clear that the agenda calls for change and demands deep and radical changes all over the world. It focuses on 17 specific goals, 169 targets, and 230 indicators (Barbier \& Burgess, 2019). SDGs are quite complex and complicated agenda but it's quite necessary because of their profound importance for human wellbeing. These goals will possibly be not achieved until and unless work by all. Therefore, the study aims to examine the effects of awareness on the economic, social, and environmental performance of government officers. The paper throws lights on the level of awareness of government officers and his/her role in achieving SDGs. Moreover, the study examines to what extent training enhances sustainable performance.

\subsection{Background of Sustainable Development Goals}

The history of SDGs started approximately 45 years back, with a pivotal United Nation conference "Conference on the Human Environment", took place in Stockholm in 1972 (UN, 2015). This was the first conference in which UN members recognizes that the economy and environment are on the collision as human activities in nature are leading to environmental risks and identical scale of the economy leading to a possibility of constant geometric growth. Later, in its emergence, the most prominent step was the Brundlandt meeting in 1983 and in the continuation, a Brundlandt commission was formulated in 1987. In commencement to this, the idea of sustainable development emerged itself. It was a tremendous breakthrough in the history of sustainable development. The commission defined sustainable development as "the development that meets the needs of the current generation without compromising the ability of the future generations to meet their own needs"(Sachs, 2015). This was based on the idea of intergenerational justice and sustainability. Simply, it expresses that the current generation has a responsibility to the future and it is to manage the lives and economy in a way that doesn't block or hinder the future generation in meeting their respective needs.

Five years later, in 1992, on the anniversary of the Stockholm Conference, the concept of Sustainable Development SD was embraced and is specifically known as Rio Earth Summit as took place in Rio de Janerio, and technically it is named the UN Conference on Environment and Development (Palmer, 2015). It was declared that SD is a shared global concept and it adopts the three major multilateral environmental agreements i.e. the UN framework convention on Climate change, the Convention on Biological Diversity for biological conversation, and the UN convention to combat desertification. In 2002, UN World Summit was organized on sustainable development in Johannesburg. Later, in 2012 , once again in Rio Conference UN members came together to discuss SD and logically claimed it as the Rio + 20 Conference. It was recognized that the concept was not really taken hold and also the three multilateral environmental agreements on combating deserts, climate, and biodiversity had not functioned properly. In this scenario, the government and its officials were called by to help place sustainable development in front of the world so that people everywhere in the world can understand its urgency and implement it. Analogous to this, the goals about fighting poverty known as Millennium Development Goals -MDGs have been adopted in the year 2000 to 2015 and were operationally but unluckily failed to achieve at the end of the years (Kumar et al., 2016). Well ahead, UN members and governments all over the world took goal-based initiatives for sustainable development and develop these goals as the extension to the MDGs. These SDGs followed the baseline of MDGs and initially approximately 300 goals were proposed that were not a practical approach and after the negotiation, these goals were compressed and 
chosen based on priority and aggregated objectives, etc. By the middle of 2015, these goals came to be seventeen (17), grounded on high-priority objectives apprehended based on social, economic, and environmental prospects (UN, 2015). These goals were embedded in the overall agenda and they become the "framework of cooperation for 2030" as these goals concentrate on the three Ps: i.e. People, Planet and Prosperity (Chams \& García-Blandón, 2019). These goals are no adopted by acclamation by all the member states (193) and they are bound to 17 Sustainable Development Goals. Each country is to prioritize and localize the goals according to their requirements.

In Balochistan, Pakistan, this is forward under the project entitled Mainstreaming, Acceleration, and Policy (MAPS) for SDGs Balochistan. The project is made a part of the Public Sector Development Plan. The objectives of the project are to lay a foundation of goal-based planning and implementation of SDGs in Balochistan, promote stock-taking/analysis of each sector (essentially covered in SDGs) on regular basis and establish necessary systems and processes for monitoring and evaluation of wider development initiatives. SDGs agenda requires collaborative efforts involving all stakeholders including government departments, civil society, private sector, and international development partners hence to make this project successful Government of Balochistan and the UN are working in coordination. The Government professionals are the main actors who share the relevant information and knowledge on Sustainable Developmental Goals (SDGs). Currently, the Government of Balochistan certifies the position in implementing SDGs and their civil officers are acting as key players in creating awareness of the 17 goals and 169 targets within the development framework.

\section{Theoretical Background and Hypotheses}

\subsection{Awareness of SDGs and Sustainable Performance}

The sustainability literature throws light on the integrated dimensions of sustainable development (Gericke et al., 2019). Sustainable development is a comprehensive concept that emphasizes the development needs of the present and future generation (Sachs, 2012). The structure is based on the economic, social, and environmental dimensions which are coherent and holistic in a balanced way. Based on this concept, the Agenda 2030 is ought to be a challenge as the approach contributes to improve the development system pertaining to the three mentioned dimensions of sustainability. To achieve Agenda 2030, the institutions are struggling to make their employees aware and understand the significance of sustainable development goals. The study of Ando et al. (2019), reveals that consciously aware employees show proactive behavior and pay more attention to process the information more accurately as compared to a person who is unaware of his surroundings. Furthermore, it is perceived that awareness increases the knowledge and perception of employees that wide his views resulting in success to achieve the goals. Respectively, the study discusses that knowledge of sustainable goals can generate economic growth (Omisore et al., 2017). The economic theme of SDGs may assist in building a welfare system that reduces poverty, create jobs, enhance performance; thus developing a robust economy (Gericke et al., 2019). Likewise, sound perspectives towards the issues of the environment enable the institutes to create healthy societies and clean surroundings. Similarly, the attentiveness towards SDGs may help in encompassing cultural and societal values (Roscoe et al., 2019). Simply, it could be concluded that information involving SDGs may help to develop pro-sustainable actions that create a peaceful, decent and secure environment. Therefore, the study proposes that when an employee is consciously aware and understands the importance of SDGs then his performance will exceed. The employee will be in a better position to deliver his work according to the respective institutional goals and the proposed agenda.

H1: Awareness of SDGs is significantly related to economic performance.

H2: Awareness of SDGs is significantly related to environmental performance.

H3: Awareness of SDGs is significantly related to social performance.

\subsection{Training as Mediator}

Agenda 2030 stimulates institutions to adopt sustainable development and make it a part of their plan and policies (Sachs, 2015)and incorporate it in their routine works. To embrace this, literature suggested 
training to be one of the ancient, and most effective practices of human resources to enhance knowledge, skills, and abilities (Noe \& Kodwani, 2018). Training is perceived to be the finest learning process that can help to deliver programs that promotes sustainable development. Lytle et al. (1998) defined it as an "increase in employee's knowledge and skills to adopt sustainable behavior". Simply, along with knowledge and awareness, skills are required that will help employees to sharpen their talents and enhance performance. Therefore, it is postulated that training programs related to three sustainable dimensions will improve and modify the capabilities as well help to achieve the triple bottom line with high propensity.

H4: Training mediates the relationship between awareness of SDGs to economic performance.

H5: Training mediates the relationship between awareness of SDGs and environmental performance.

H6: Training mediates the relationship between awareness of SDGs to social performance.

\section{Methodology}

The research is conducted in the public sector located in Balochistan. The population of the study comprises of top government officials that covered the services provided to the stakeholders including line departments, civil societies, private institutes as well as common public. The department act as a hub of SDGs activities. The total population comprises of 331 employees and out of which 269 employees responded to the questionnaires, which were distributed among the participants. The questionnaire was adopted from different studies. To measure awareness of Sustainable Development Goals the five questions with a "5 points Likert scale" ranging from "strongly agree (1) to strongly disagree (5)" were adapted from Ando et al. (2019). Similarly, training scale adopted from Lytle et al. (1998)study comprises of 3 items also composed on a "5 points Likert scale". Lastly, the dependent variables, measures adapted from Lee and Ha-Brookshire (2018) study, based on individual perception and composed of 8 items with a "5 point Likert scale.

The data collected was primarily analyzed in Social Sciences Statistical Package (IBM-SPSS) version 23. Subsequently, structural equation modeling is applied to test the model and for analysis, Smart-PLS software is used. PLS-SEM (Partial Least Squares- Structural Equation Modeling) is extensively applied in management sciences (Hair et al., 2019). Generally, it holds a higher level of statistical power and it is most appropriate when predicting the variables.

\section{Results}

\subsection{Demographic Characteristics}

The data screened for missing values and outliers. The response rate of the study was calculated as $81 \%$. The data on demographics characteristics showed that most of the participants were male. Likewise, $45.4 \%$ of the participant's age lies between 28 to 37 years. Approximately, $86.2 \%$ of the employees attained a Master degree. The assumptions relating to normality were assessed. Table 1 represents the statistics. According to Hair et al. (2019), the acceptable values of skewness fall between -3 and +3 , and kurtosis is appropriate from a range of -10 to +10 when utilizing SEM.

Table 1: Descriptive Statistics

\begin{tabular}{lcccc}
\hline Variable $(\mathbf{N = 2 6 9 )}$ & Mean & Std. Deviation & Skewness & Kurtosis \\
\hline Sdgs_01 & 3.860 & 0.696 & -0.810 & 1.581 \\
Sdgs_02 & 3.870 & 0.701 & -0.737 & 1.788 \\
Sdgs_03 & 4.030 & 0.660 & -0.968 & 3.317 \\
Sdgs_04 & 3.120 & 0.972 & -0.380 & -0.714 \\
Sdgs_05 & 2.950 & 1.028 & -0.061 & -0.863 \\
EcoP_01 & 3.830 & 0.763 & -0.867 & 1.623 \\
EcoP_02 & 3.740 & 0.739 & -0.767 & 1.165
\end{tabular}




\begin{tabular}{lllll} 
EcoP_03 & 3.900 & 0.829 & -0.760 & 0.723 \\
EnrP_01 & 4.010 & 0.605 & -0.721 & 2.234 \\
EnrP_02 & 4.070 & 0.654 & -1.115 & 3.521 \\
EnrP_03 & 3.870 & 0.747 & -0.817 & 1.194 \\
SocP_01 & 4.400 & 0.630 & -1.096 & 2.513 \\
SocP_02 & 4.480 & 0.667 & -1.371 & 2.405 \\
Train_01 & 3.700 & 0.834 & -0.706 & 0.365 \\
Train_02 & 3.930 & 0.685 & -0.893 & 2.064 \\
Train_03 & 3.880 & 0.681 & -0.920 & 2.024 \\
\hline
\end{tabular}

** SDGs=Awareness of Sustainable Development Goals, EcoP=Economic Performance, EnrP=Environmental Performance, SocP=Social Performance, Train=Training

The study applied a self-reporting scale that may create uncertainty of common method bias. To test the issue, Harman`s single factor test (Podsakoff \& Organ, 1986) performed that scored 34.581(\% of variance) indicating that no serious issue prevails. Further, two step-method of SEM was applied to test the model which elucidates measurement and structural assessment.

\subsection{Structure Equation Modeling: Measurement Model Assessment}

The measurement model comprises of individual item reliability, internal consistency, content, convergent and discriminant validity. The indicator reliability examines the loading of construct items that retain the value of 0.7 or greater (Hair et al., 2019). Similarly, the internal consistency, the composite reliability, rho A and Cronbach`s alpha are also examined that yield an acceptable range of values. For instance, the average variance extracted (AVE) scored at least $0.50 \mathrm{or} /$ and more(Umrani et al., 2018). Table 1 shows the values of the measures that lie in an acceptable range.

Table 2: Evaluation of the Measurement Model

\begin{tabular}{|c|c|c|c|c|c|c|}
\hline Variables name & Item Label & Factor Loading & Cronbach's Alpha & rho_A & $\mathbf{C R}$ & AVE \\
\hline \multirow[t]{6}{*}{ Awareness of SDGs } & & & 0.784 & 0.799 & 0.853 & 0.540 \\
\hline & Sdgs_01 & 0.816 & & & & \\
\hline & Sdgs_02 & 0.828 & & & & \\
\hline & Sdgs_03 & 0.697 & & & & \\
\hline & Sdgs_04 & 0.631 & & & & \\
\hline & Sdgs_05 & 0.680 & & & & \\
\hline \multirow[t]{4}{*}{ Economic Performance } & & & 0.779 & 0.779 & 0.872 & 0.694 \\
\hline & EcoP_01 & 0.835 & & & & \\
\hline & EcoP_02 & 0.866 & & & & \\
\hline & EcoP_03 & 0.797 & & & & \\
\hline \multicolumn{2}{|c|}{ Environmental Performance } & & 0.806 & 0.813 & 0.885 & 0.721 \\
\hline & EnrP_01 & 0.806 & & & & \\
\hline & EnrP_02 & 0.879 & & & & \\
\hline & EnrP_03 & 0.860 & & & & \\
\hline \multirow[t]{3}{*}{ Social Performance } & & & 0.924 & 0.932 & 0.963 & 0.929 \\
\hline & SocP_01 & 0.960 & & & & \\
\hline & SocP_02 & 0.968 & & & & \\
\hline \multirow[t]{3}{*}{ Training } & & & 0.755 & 0.780 & 0.861 & 0.676 \\
\hline & Train_01 & 0.706 & & & & \\
\hline & Train_02 & 0.893 & & & & \\
\hline
\end{tabular}


Train_03

0.855

** SDGs=Awareness of Sustainable Development Goals, EcoP=Economic Performance, EnrP=Environmental Performance, SocP=Social Performance, Train=Training

The discriminant validity can be measured by three criteria ascribed as Fornell and Larcker, Cross loading, and Heterotrait-monotrait (HTMT) ratio. Literature put forth that the two foremost criterions performance is poor in unfolding discriminant validity problems (Hair et al., 2012). However, HTMT claimed to be a more acceptable criterion of discriminant validity. Table 3 represents the values of HTMT that did not exceed 0.85 or 0.90 respectively.

Table 3: Discriminate Validity (Heterotrait-Monotrait Criteria)

\begin{tabular}{llllll}
\hline & $\begin{array}{l}\text { Awareness of } \\
\text { SDGs }\end{array}$ & $\begin{array}{l}\text { Economic } \\
\text { Performance }\end{array}$ & $\begin{array}{l}\text { Environmental } \\
\text { Performance }\end{array}$ & $\begin{array}{l}\text { Social } \\
\text { Performance }\end{array}$ & Training \\
\hline $\begin{array}{l}\text { Awareness of SDGs } \\
\text { Economic }\end{array}$ & & & & \\
$\begin{array}{l}\text { Performance } \\
\text { Environmental }\end{array}$ & 0.578 & & & \\
$\begin{array}{l}\text { Performance } \\
\text { Social Performance }\end{array}$ & 0.568 & 0.390 & 0.383 & & \\
Training & 0.403 & 0.418 & 0.383 & \\
\hline
\end{tabular}

\subsection{Structural Model Assessment and Hypothesis Testing}

The structural model is the assessment of path coefficients. The standard assessment criteria for measuring the structural model is by calculating multicollinearity, significance value (p), coefficient of determination $\left(\mathrm{R}^{2}\right)$, effect size $\left(f^{2}\right)$, and predictive relevance $\left(\mathrm{Q}^{2}\right)$ (Hair et al., 2012). The collinearity issues were addressed to ensure biasness and ideally, the VIF values examined to be close to 3 and lower. Further, the standard bootstrapping procedure with 5000 bootstrapping samples and 269 cases were run to determine the significance and relevance of the structural model relationship. The result indicated that the direct and indirect effects of all the hypothesized relationships are significant. Figure1 demonstrates a significant relationship among the constructs. The hypothesis $\mathrm{H} 1$ results represent a positive and significant relationship between awareness of SDGs and economic performance with $(\beta=0.401, \mathrm{t}=4.779, \mathrm{p}$ $<0.00)$. Similarly, hypothesis $\mathrm{H} 2$ is also supported, which signifies that awareness of SDGs and environmental performance are significantly related $(\beta=0.399, \mathrm{t}=6.625, \mathrm{p}<0.00)$. Further, hypothesis H3 explains the relationship between awareness of SDGs and social performance. The results for this hypothesis also supported $(\beta=0.267, \mathrm{t}=4.548, \mathrm{p}<0.00)$. Likewise, the hypotheses $\mathrm{H} 4$, H5, and H6 related to mediation are also supported i.e. training plays a significant role in mediating the relationship among awareness of SDGs, economic $(\beta=0.062, t=2.330 \mathrm{p}<0.02)$, environmental $(\beta=0.061, \mathrm{t}=2.196, \mathrm{p}<0.02)$ and social $(\beta=0.070, \mathrm{t}=2.990, \mathrm{p}<0.00)$ performance. Further, to measure the model proportion of variation, the level of coefficient of determination $\left(R^{2}\right)$ is assessed. The values of adjusted $R^{2}$ are sufficient according to the proposed range i.e. between 0 and 1 . The variation of $24.0 \%$ is seen in economic performance, $30.0 \%$ in environmental performance. $15.0 \%$ in social performance whereas $10.2 \%$ variation is explained through training. This is an acceptable range as literature revealed that the value of $\mathrm{R}^{2}$ depends on the discipline and field of study (Falk \& Miller, 1992). Lastly, the predictive relevance $\left(\mathrm{Q}^{2}\right)$ of exogenous constructs using the blindfolding procedure was analyzed. According to the rule of thumb, the values of $0.02,0.15$, and 0.35 indicate small, medium, and large predictive relevance respectively. The predictive relevance of the constructs of this study is demonstrated in Table 4.

Table: 4: Construct Cross-Validated Redundancy $\left(Q^{2}\right)$

\begin{tabular}{llll}
\hline & SSO & SSE & $\mathbf{Q}^{2}(=1-S S E / S S O)$ \\
\hline Economic Performance & 807 & 681.829 & 0.155 \\
Environmental Performance & 807 & 676.640 & 0.162
\end{tabular}




\begin{tabular}{llll} 
Social Performance & 538 & 464.938 & 0.136 \\
Training & 807 & 753.142 & 0.067 \\
\hline
\end{tabular}

The study also assesses the effect size $f^{2}$ and according to the rule of thumb, if $f^{2}<0.02$; this means no effect whereas $f^{2}=$ or $>0.02$ to $<0.15$ means weak effect. Similarly, $f^{2}=$ or $>0.15$ to $<035$, then it is considered as moderate effect. Lastly, if $f^{2}>035$, it represents a strong effect. The results of effect size $f^{2}$ is satisfactory and are represented in Table 5. 
Table 5: Testing Hypothesis Using Path Coefficients

\begin{tabular}{|c|c|c|c|c|c|c|c|c|c|c|}
\hline Нyp & Relationship & $\begin{array}{l}\text { Std } \\
\text { Beta }\end{array}$ & $\begin{array}{l}\text { Std } \\
\text { Error }\end{array}$ & t-value & $\begin{array}{l}\text { p- } \\
\text { value }\end{array}$ & $f^{2}$ & $\begin{array}{l}2.5 \% \\
\mathbf{L L}\end{array}$ & CI & $\begin{array}{l}97.5 \% \\
\text { UL }\end{array}$ & CI \\
\hline H1 & Awareness of SDGs -> Economic Performance & 0.401 & 0.082 & 4.779 & 0.000 & 0.181 & 0.205 & & 0.527 & \\
\hline H2 & Awareness of SDGs -> Environmental Performance & 0.399 & 0.059 & 6.625 & 0.000 & 0.182 & 0.265 & & 0.499 & \\
\hline H3 & Awareness of SDGs -> Social Performance & 0.267 & 0.058 & 4.548 & 0.000 & 0.074 & 0.136 & & 0.370 & \\
\hline H4 & Awareness of SDGs -> Training -> Economic Performance & 0.062 & 0.028 & 2.330 & 0.020 & 0.048 & 0.016 & & 0.127 & \\
\hline H5 & $\begin{array}{l}\text { Awareness of SDGs } \rightarrow \text { Training } \rightarrow \text { Environmental } \\
\text { Performance }\end{array}$ & 0.061 & 0.027 & 2.196 & 0.028 & 0.040 & 0.016 & & 0.120 & \\
\hline H6 & Awareness of SDGs -> Training -> Social Performance & 0.070 & 0.023 & 2.990 & 0.003 & 0.051 & 0.031 & & 0.124 & \\
\hline
\end{tabular}

Note: $* * * \mathrm{p} \leq 0.001 ; * * \mathrm{p} \leq 0.05 ; * \mathrm{p} \leq 0.01$.

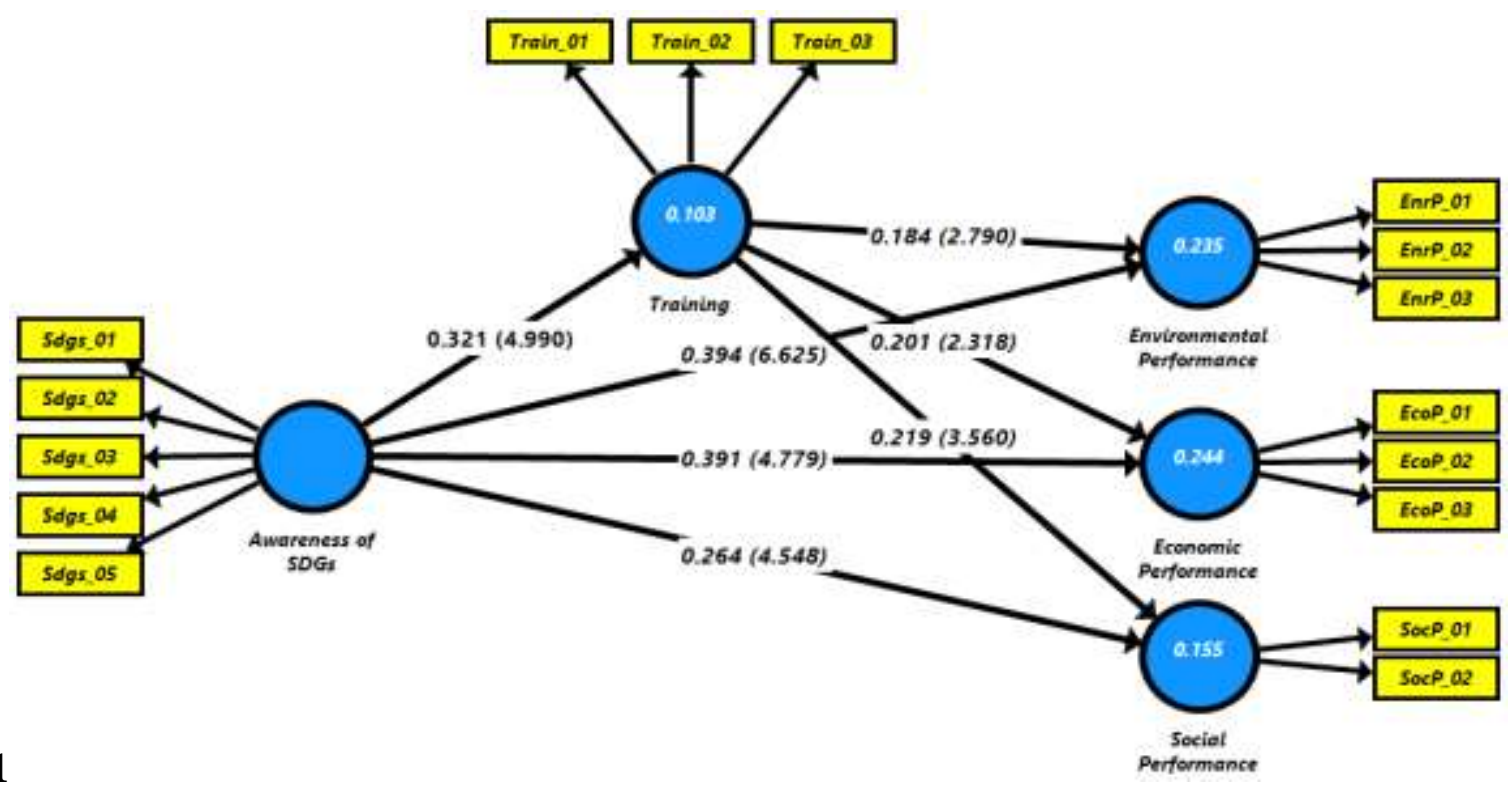

Figure 1

Social
Performance 


\section{Discussion and Conclusion}

The study exemplifies the standardized parameter estimates for the structural model and the significance levels of each relation. Nearly, all the hypotheses proved to be significantly positive. The results of the study also correspond with literature that awareness of sustainable development goals stimulates employees to engage in economic and social activities and support to sustain the resources. Participating in environmental activities also enhances the preservation qualities of employees and they perform well in sustaining their surroundings.

Simply, defining and delineating awareness of SDGs helps to leverage employee's motivation to serve in public interests at a global scale. It inspires employees to perform towards a social cause, generate revenues, and preserve the environment. Further, the evidence of the study showed through better training programs employees perform better as they are more engaged and committed to achieve SDGs. Training boosts the performance as it is based on the combination of personality traits and organizational needs and state (Ji et al., 2012). Training awakens the sense of purpose and mission in public employees (Noe \& Kodwani, 2018). Thus, learning development experiences are a way to preserve cutting-edge knowledge and keep motivation and engagement high.

The study also describes that enhancement and achievement not only depend on individual preferences, inclinations, attitudes, but it is also a product of the organizational culture and organizational settings that are conveyed through learning practices and programs. Thus, the practical implications of the study are to create a remarkable sustainable performance. Institutions needed to attract and select employees with a higher level of awareness (Omisore et al., 2017). Additionally, knowledge and technical skills are important and fundamental for serving the public and achieving goals. Therefore, public institutions ought to nurture their employees and focus to systematically build capacity, make perceptions and break down SDGs into meaningful targets to evaluate organizational and individual performance on achievable metrics.

Henceforth, recommended that researchers may focus on introducing outcome-oriented organizational performance metrics that link individual sustainable performance metrics to better communicate linkages between goal accomplishment and public value creation (Lopez-Cabrales \& Valle-Cabrera, 2020). Furthermore, researchers may even design impact-oriented, interactive, and integrated professional tasks, to enable employees to serve the public and unlock bureaucracies to create a decent workplace that supports sustaining the resources and enhance performance (Deslatte \& Swann, 2020). Lastly, researchers may develop models by incorporating more rigorous HR practices that help in examining the association of SDGs with other relevant institutional outcomes(Roscoe et al., 2019).

The limitation of the study is that the information is gathered from public sector institutions only, so it is not generalizable to the private sector, civil societies, and non-profit institutes. It is a cross-sectional study that means data is gathered at one point, so it is preferred for more accurate results the study must be conducted for a longer period.

\section{References}

Ando, Y., Baars, R. C., \& Asari, M. (2019). Questionnaire survey on consciousness and behavior of students to achieve SDGs in Kyoto University. Journal of Environment and Safety, 10(2), 21-25.

Barbier, E. B., \& Burgess, J. C. (2019). Sustainable development goal indicators: Analyzing trade-offs and complementarities. World development, 122, 295-305.

UN. (2015). Transforming our world: the 2030 Agenda for Sustainable Development.

Chams, N., \& García-Blandón, J. (2019). On the importance of sustainable human resource management for the adoption of sustainable development goals. Resources, Conservation and Recycling, 141, 109-122.

Deslatte, A., \& Swann, W. L. (2020). Elucidating the linkages between entrepreneurial orientation and local government sustainability performance. The American Review of Public Administration, 50(1), 92-109. 
Falk, R. F., \& Miller, N. B. (1992). A primer for soft modeling. University of Akron Press.

Gericke, N., Boeve-de Pauw, J., Berglund, T., \& Olsson, D. (2019). The Sustainability Consciousness Questionnaire: The theoretical development and empirical validation of an evaluation instrument for stakeholders working with sustainable development. Sustainable Development, 27(1), 35-49.

Hair, J. F., Risher, J. J., Sarstedt, M., \& Ringle, C. M. (2019). When to use and how to report the results of PLS-SEM. European business review.

Hair, J. F., Sarstedt, M., Ringle, C. M., \& Mena, J. A. (2012). An assessment of the use of partial least squares structural equation modeling in marketing research. Journal of the academy of marketing science, 40(3), 414-433.

Huan, Y., Li, H., \& Liang, T. (2019). A new method for the quantitative assessment of Sustainable Development Goals (SDGs) and a case study on Central Asia. Sustainability, 11(13), 3504.

Ji, L., Huang, J., Liu, Z., Zhu, H., \& Cai, Z. (2012). The effects of employee training on the relationship between environmental attitude and firms' performance in sustainable development. The International Journal of Human Resource Management, 23(14), 2995-3008.

Kumar, S., Kumar, N., \& Vivekadhish, S. (2016). Millennium development goals (MDGS) to sustainable development goals (SDGS): Addressing unfinished agenda and strengthening sustainable development and partnership. Indian journal of community medicine: official publication of Indian Association of Preventive \& Social Medicine, 41(1), 1.

Lee, S. H., \& Ha-Brookshire, J. (2018). The effect of ethical climate and employees' organizational citizenship behavior on US fashion retail organizations' sustainability performance. Corporate Social Responsibility and Environmental Management, 25(5), 939-947.

Lopez-Cabrales, A., \& Valle-Cabrera, R. (2020). Sustainable HRM strategies and employment relationships as drivers of the triple bottom line. Human resource management review, 30(3), 100689.

Lytle, R. S., Hom, P. W., \& Mokwa, M. P. (1998). SERV* OR: A managerial measure of organizational service-orientation. Journal of retailing, 74(4), 455-489.

Noe, R. A., \& Kodwani, A. D. (2018). Employee training and development, 7e. McGraw-Hill Education.

Omisore, A. G., Babarinde, G. M., Bakare, D. P., \& Asekun-Olarinmoye, E. O. (2017). Awareness and knowledge of the sustainable development goals in a university community in southwestern Nigeria. Ethiopian journal of health sciences, 27(6), 669-676.

Oosterhof, P. D. (2018). Localizing the sustainable development goals to accelerate implementation of the 2030 agenda for sustainable development.

Palmer, E. (2015). Introduction: The 2030 Agenda. Journal of Global Ethics, 11(3), 262-269.

Podsakoff, P. M., \& Organ, D. W. (1986). Self-reports in organizational research: Problems and prospects. Journal of management, 12(4), 531-544.

Roscoe, S., Subramanian, N., Jabbour, C. J., \& Chong, T. (2019). Green human resource management and the enablers of green organisational culture: Enhancing a firm's environmental performance for sustainable development. Business Strategy and the Environment, 28(5), 737-749.

Sachs, J. D. (2012). From millennium development goals to sustainable development goals. The lancet, 379(9832), 2206-2211.

Sachs, J. D. (2015). The age of sustainable development. Columbia University Press.

Umrani, W. A., Kura, K. M., \& Ahmed, U. (2018). Corporate entrepreneurship and business performance. PSU Research Review. 